\title{
A dor e a constituição psíquica
}

\author{
Ana Celina Garcia Albornoz.1 \\ Maria Lúcia Tiellet Nunes
}

\begin{abstract}
Resumo
Este artigo aborda uma temática que atinge a todos: a infância e a adolescência marcadas pelas privações. O abandono, a negligência e o abuso físico, sexual e psicológico de crianças e de adolescentes são fatos reais e freqüentes na vida dos mesmos. A literatura psicanalítica sustenta a idéia de que as vivências de privação geram importantes seqüelas no desenvolvimento emocional, podendo marcar de forma peculiar a vida das pessoas para sempre. O percurso teórico realizado neste artigo aponta que crianças e adolescentes vitimizados apresentam dificuldades para investir em si mesmos e nos outros, o que os torna portadores de sintomas dificultadores da adaptação pessoal, social, escolar, institucional e familiar. É fundamental que eles possam elaborar as suas vivências passadas traumáticas, retomar o desenvolvimento de forma saudável e atualizar os seus potenciais.

Palavras-Chave: Desamparo; Privação; Infância; Atrasos desenvolvimentais; Comportamentos violentos.
\end{abstract}

\section{The pain and the psyché's constitution}

\begin{abstract}
This paper concerns a theme which affects everyone: childhood and adolescence at risk. Abandonment, neglect as well as physical, sexual and psychological abuse of children and adolescents are real and often recurrent in their lives. Psychoanalytic literature sustains the idea that early experiences of deprivation cause important sequels to emotional development and might leave everlasting consequences. The theoretical approach developed in this study shows that children and adolescents who are victimized present difficulties investing in themselves and in others. As a result, they present symptoms of difficult adjustment in personal, social, school, institutional and family areas. It is essential for them to overcome such traumatic past experiences in order to enable such children and adolescents to develop in a more healthier way and to enhance their potential.

Keywords: Helplessness; Deprivation; Childhood; Developmental delay; Violent behavior.
\end{abstract}

Este artigo se propõe a abordar os efeitos das experiências traumáticas na constituição do psiquismo e, para tanto, realiza uma revisão acerca das bases desenvolvimentais que tornam possível o vir-a-ser um sujeito psíquico, bem como também analisa as experiências invasivo-desestruturantes dos vitimizados. $\mathrm{O}$ conhecimento da trajetória histórica de um indíviduo propicia a compreensão das marcas estruturais que dão sentido ao todo do seu ser.

A literatura psicanalítica reconhece que a personalidade saudável decorre de um desenvolvimento suficientemente bom nos primeiros anos de vida. Em suas obras, Bollas (1992), Bowlby (1988, 1990), Spitz (1988) e Winnicott $(1987,1988)$ pontuam que o ambiente tem importância determinante no desenvolvimento da criança. Inicialmente, a mãe é o ambiente do bebê; sua presença, continuidade e consistência são decisivos para a estruturação do psiquismo da criança. A fragilidade do bebê humano impõe a necessidade de um outro que lhe assegure as condições mínimas de sobrevivência. A impotência psicomotora do recém-nascido e sua condição originária de dependência do outro marcarão todo o desenvolvimento posterior de sua estrutura subjetiva (Kon, 2000).

A impossibilidade do bebê de cuidar de si gera desprazer em razão do acúmulo de tensão pulsional. O desprazer exige a organização de uma estrutura psíquica complexa, destinada a lidar com esses desequilíbrios. A atividade mental é determinada pela busca do prazer, que, por meio de uma ação psíquica que promove uma descarga, atribui significados mentais às pulsões, inserindo-as no campo da experiência emocional. A dor destinada a trazer desconforto e sofrimento - pode ser percebida no corpo ou sentida na alma, como uma sensação, percepção ou um sentimento, que informa ao self a respeito do que lhe é desconfortante. Dessa forma, o self é levado a buscar uma resposta restabelecedora que venha a protegê-lo do acontecimento que ameaça o seu equilíbrio (Dantas, 1999).

O primeiro movimento psíquico da criança é projetar no objeto o que lhe causa dor, reintrojentandoo posteriormente, já transformado. No início do

\footnotetext{
${ }^{1}$ Endereço para correspondência:

Av. Cristóvão Colombo, 2.978/405 - Bairro Higienópolis

90560-002 - Porto Alegre-RS

E-mail: anaalbaornoz@cpovo.net
} 
desenvolvimento, os bebês expressam a sua dor por meio de sinais - sobressaltos, gemidos, expressões faciais - que vão sendo significados para eles pela escuta de suas mães - objeto continente pensante complementar -, tornando possível a sua transformação em representações mentais que, sucessivamente, formarão núcleos de integração mental, instaurando o processo de humanização. Esse objeto fundante empresta a sua subjetividade ao bebê, revelando-lhe a sua dor e, ao fazê-lo, serve como um instrumento para que ele a transforme, significando-a e integrando-a. A expansão do acervo de representações mentais, articuladas mediante processos de deslocamentos e condensações, fornecerá o suporte necessário para que o aparelho psíquico faça frente à natureza desconhecida e insuportável da dor (França, 1999).

A mãe, que por suas percepções e reações expressivas tem a função de recepção e comunicação dos estados emocionais primordiais da existência, constitui-se num instrumento afetivo para a elaboração e transformação das vivências do bebê (Melsohn, 2001). Valendo-se do amor da mãe e de sua capacidade empática, o bebê organiza as suas pulsões libidinais e agressivas, inaugura o simbólico e se constitui como sujeito psíquico. Eis a função primordial da maternagem: apoiado no ego da mãe, o bebê satisfaz as suas necessidades, contém a sua angústia e internaliza padrões de comportamento, prosseguindo o desenvolvimento de sua personalidade (Winnicott, 1988). Winnicott (1988) chama esse cuidado de bolding. Bollas (1992) denomina a mãe de objeto transformacional porque ela é experienciada como um processo que promove a integração do ser instintivo, cognitivo, afetivo e ambiental do infante pela alteração do meio. Ela transforma o vazio, a agonia e a raiva do bebê em plenitude e contentamento. Tal função é herdada pelo ego, posteriormente. É por este motivo que as atitudes do ego indicam o traço daquela relação objetal e contêm a história do desenvolvimento da pessoa. Ocorre uma transição da privacidade para o meio cultural, que prosseguirá por toda a vida: a forma como a mãe conduziu o infante determinará como ele conduzirá seu self e se relacionará com os demais (Bollas, 1992).

As primeiras relações objetais têm importância crucial para a estrutura social, pois a capacidade para o estabelecimento de relações interpessoais tem origem na relação mãe-filho (Spitz, 1988). O investimento libidinal, dispensado pela função materna, levará a criança a constituir uma identidade subjetiva que conterá as marcas das relações estabelecidas com o mundo externo. A história do sujeito refletirá os encontros e desencontros, os desencadeamentos pulsionais - vida e morte, amor e ódio - e as ligações e desligamentos que ele vivenciou na relação com o outro (Pires, 1999). Sendo essa relação precursora tão fundamental para a constituição do psiquismo, há de se refletir acerca de uma questão: os efeitos da violência de qualquer ordem contra crianças e adolescentes. A onipresença da violência nas relações sociais, e em especial nas circunstâncias de vitimização na infância, com certeza dizem algo sobre a cultura de uma sociedade que, por conseguinte, diz algo sobre as relações objetais desta mesma sociedade.

Os efeitos prejudiciais das privações vivenciadas na infância dos indivíduos para a construção da sociedade têm levado a comunidade científica mundial a concentrar esforços para o seu entendimento. Nos últimos anos, este tema tem sido amplamente divulgado nos meios de comunicação do mundo inteiro. No Brasil, a internet, os programas de televisão, as revistas e os jornais de grande circulação delatam a situação de vitimização que atinge crianças e adolescentes do país. A expectativa é de que o debate público contribua para amenizar o problema, problema esse que tem raízes profundas na nossa sociedade.

Pesquisando a trajetória histórica das crianças no Brasil, se constata a presença de privações na infância desde o início da história do país. A partir de 1530, quando as terras do Brasil começaram a ser povoadas, as embarcações lusitanas que aqui chegavam traziam muitas crianças solitárias a bordo. As familias portuguesas pobres empregavam os seus filhos para servirem nessas embarcações, abandonando-os à própria sorte. Durante a viagem, as crianças solitárias eram privadas de alimentação, expostas a um ambiente insalubre, escravizadas, abusadas sexualmente e severamente castigadas por marujos violentos. As que sobreviviam, traziam as marcas dos traumas vividos e faziam das ruas o seu lar e ganha-pão (Priore, 1999).

Ainda hoje, as privações são fatos reais e freqüentes na vida das crianças brasileiras, cujas marcas determinarão as trajetórias de suas vidas e a conformação das suas personalidades; pois com base nas experiências de satisfação ou de frustração de suas necessidades, o bebê registra sensações e percepções que, mesmo ocultos, constituem a memória e determinam as pautas de conduta de uma pessoa (Freud, 1895/1980a). Têm-se, então, as marcas protocoladas pelas experiências de privações.

Quando as experiências predominantes são traumáticas, elas envolvem um nível de angústia intolerável ao ego, de modo que invadem os processos normais (Albornoz, 2001), promovendo a destruição completa ou parcial do aparelho mental em desenvolvimento ou já desenvolvido e do senso de identidade, culminando na deformação da mente (Shengold, 1999) ou mesmo na morte do indivíduo (Spitz, 1988). A intensa e irremediável dor, expressão do estado de desprazer presente nas experiências traumáticas, consiste na irrupção de uma estimulação excessiva e contínua e numa falha significativa dos mecanismos de proteção, sendo causadora de dano ao aparelho psíquico (Freud, 1920/1980b). Mesmo que o desenlace da teoria freudiana tenha redimensionado o 
peso da realidade factual em favor da realidade psíquica, essa experiência violenta caracteriza-se como invasiva, pelo seu caráter prejudicial e desnecessário ao ego (Aulagnier, 1975/2001). Sob condições traumáticas, o psiquismo pode excluir o excesso pulsional do campo das representações, determinando a constituição de modos primários de organização em que marcas ficam inscritas no corpo. Cabe, então, à realidade corporal manter registradas as marcas dessa história (Aulagnier, 1975/2001; M. Pires, 1999).

A dor psíquica, decorrente da perda real ou fantasiada de um objeto (Freud, 1920/1980b), provoca uma reação, recrudesce defesas ameaçando as catexias objetais e as tendências de ligação, pondo em risco toda a capacidade de um indivíduo para estabelecer vínculos (Dantas, 1999). Baseando-se em Bion, André Green e Meltzer, França (1999) afirma que a dor provocada por uma decepção sofrida num momento de desamparo produz um sofrimento profundo. Pessoas para quem os objetos primários falharam em oferecer condições suficientemente boas para o seu desenvolvimento nos primórdios da vida psíquica permanecerão afogadas no desespero pela vida toda. Nessa categoria estão incluídos os abusos, que sempre deixam marcas, são excessivos ao ego e danosos à personalidade.

Ao conceituar-se a vivência abusiva, conclui-se que ela é decorrente de uma falha na função materna de "tela protetora" para o bebê ou para a criança, que não os protege do que é excessivo, ocasionando-lhes imensa dor. $\mathrm{O}$ abuso se caracteriza pela submissão de alguém mais frágil ao desejo de um outro mais forte, podendo o primeiro moldar-se a esse uso ou não (Albornoz, 2001). Além disso, pode ocorrer o abuso subjetivo, no qual os pais projetam elementos cindidos e indesejados do seu self no self de sua criança, sobrecarregando-a com um mundo interno caótico. Esse processo de invasão, que representa um roubo do mundo interno, deixa um espaço vazio na mente que será armazenado na memória sem a devida compreensão e poderá desencadear sentimentos de indiferença, vazio, raiva, depressão ou paranóia (Bollas, 1992). Os conteúdos mentais, produtos ou registros de incorporação de experiências de violência - excessos de penetração, excitação intrusiva - encontram-se cindidos e são sentidos como corpos estranhos na mente (França, 1999). Esse sentimento de estranheza ocasiona uma perda da percepção de sua própria pessoa, uma perda de sua história, que remete à perda de uma parte do self (Bollas, 1992). Tais prejuízos ao psiquismo podem ser decorrentes de mazelas de diversas ordens.

$\mathrm{O}$ abuso físico se caracteriza por punições envolvendo o uso da força física, que normalmente deixam marcas no corpo da criança e comumente são justificadas como medidas educativas (AMAS, 2000; EPOCH, 1993; Farinatti, Biazus \& Leite, 1993; J. Pires, 1999).
O abuso sexual pode ser definido como qualquer envolvimento do indivíduo em atividades sexuais com ou sem contato físico - exposição, manipulação, penetração, exploração - que ele não compreende ou para as quais ainda não tem maturidade (Farinatti e colaboradores, 1993; Furniss, 1993). A ocorrência mais freqüente acontece no meio intrafamiliar (Acosta, Adúriz \& Albarracín, 1998; J. Pires, 1999), podendo ser encoberta por atitudes nomeadas como intimidade e carinho (Ammerman e Hersen, 1999; Farinatti e colaboradores, 1993; J. Pires, 1999). Atualmente, segundo Laia (2001), um imperativo categórico - falar sobre sexo e praticar sexo - transforma a perversão em norma acatada. Pontua que um fenômeno tem atingido a sociedade brasileira: os pais extasiam-se diante do rebolado sensual dos corpos dos filhos influenciados pela proposta da programação televisiva destinada ao público infantil, enquanto repudiam a masturbação própria da sexualidade infantil. $\mathrm{O}$ autor explica que os adultos impõem à criança algo da ordem do sexual, enquanto ela, surpresa e curiosa, implica-se nesse encontro com respostas reais. Ela acolhe em seu corpo o gozo do outro, deixando-se incitar por essa estranha e familiar satisfação, chegando até a provocála, a se deixar extasiar, a se deixar marcar. A criança prostituída torna-se objeto capturado pelas fantasias da subjetividade da atualidade, sendo destituída de sua própria infância. Nesses casos, a perversão abarca a infância.

A negligência ocorre quando os pais ou responsáveis falham em prover as necessidades básicas saúde, alimentação, educação, afeto, respeito - de uma criança ou um adolescente. Há uma desatenção quanto a aspectos importantes no cuidado da criança, tal como a falta de proteção ou o descaso para com as suas necessidades evolutivas. Porém, a definição de negligência deve levar em conta as diferenças práticas de socialização de cada contexto cultural ao qual se aplica (Martínez, 1997). A negligência acontece quando as relações de cuidado são inexistentes ou inadequadas. A perda dos cuidados maternos pode ocorrer mesmo quando não houve uma separação real, mas perda do amor, oscilação ou rejeição (Bowlby, 1988; Spitz, 1988). Essa falta de atenção, muitas vezes, é falsamente justificada pela falta de tempo dos pais (Farinatti e colaboradores, 1993; J. Pires, 1999).

O abuso emocional está presente, de alguma forma, em todas as modalidades de privações vivenciadas pelos indivíduos. As repetitivas e inapropriadas respostas emocionais e comportamentais às experiências infantis se caracterizam como abuso emocional. Ambientes familiares continuamente rígidos, controladores, superprotetores ou caóticos podem ser considerados emocionalmente perturbadores do desenvolvimento emocional das crianças (Kent e Waller, 2000). Tanto para Aulagnier (1975/2001; 1984/1989), como para Mannoni (1985), a falta de desejo materno torna a realidade da criança muito frustrante. 
Os maus-tratos psicológicos podem se manifestar por meio de rejeição, depreciação, discriminação, desrespeito, utilização da criança para atender às necessidades psicológicas dos adultos, cobranças e punições exageradas. Esse tipo de maus-tratos, embora grave e freqüente, tem difícil caracterização (ABRAPIA, 1997). Portanto, violência é todo o ato ou omissão - violência psicológica, negligência - praticados por pais ou responsáveis, que podem causar dano físico, sexual e psicológico à vítima, que implicam uma transgressão do poder e uma negação dos direitos da criança e do adolescente (AMAS, 2000; EPOCH, 1993; Farinatti, e colaboradores, 1993; J. Pires, 1999).

$\mathrm{O}$ exposto permite a constatação de que o problema do desamparo não está dado exclusivamente pela incompetência do bebê em garantir a sua sobrevivência mediante seus próprios meios, mas fundamentalmente pela condição na qual se dá o encontro do bebê desamparado com o adulto provedor, já marcado pelo seu inconsciente e pela sua sexualidade. $O$ bebê se entrega ao adulto como uma forma de garantir a sua sobrevivência. No ímpeto de triunfar sobre a sua própria história de desamparo, o adulto atribui ao outro a fraqueza e a insegurança que deseja excluir de si próprio, reassegurando assim o seu próprio narcisismo (Pereira, 2000). Nesses casos, o adulto transgride os limites de elaboração e de subjetivação da criança, não respeitando a sua natureza infantil de reconhecimento de estímulos externos, invadindo-a com a sua sexualidade (M. Pires, 1999) e submetendo-a a uma vivência traumática impossível de ser simbolizada. Os indivíduos desamparados se transformam em objetos de gozo e em vítimas da violência não somente graças à sua fragilidade, mas sobretudo em virtude das pulsões recalcadas no outro (Pereira, 2000). Sendo assim, pode-se dizer que os traços que caracterizam o ser humano - sua personalidade, sua forma de pensar, de se comportar - não se constroem no vazio, assim como também não são uma reprodução direta do que é a família, mas constituem-se nas relações sociais de interdependência (Zago, 2000). O grupo familiar pode determinar a possibilidade ou a impossibilidade de saúde dos seus membros. As tensões internas da família podem ser drenadas através de um de seus membros; geralmente essa sobrecarga recai sobre o membro mais frágil. A criança, pela sua condição de vulnerabilidade, dificilmente consegue escapar dos papéis que precocemente lhe são atribuídos pela família. Assumir esses papéis pode constituir-se na sua única forma de sobrevivência possível (Costa, 1999; Ortigues \& Ortigues, 1988).

A definição do valor do fator traumático deve necessariamente levar em conta o funcionamento $a$ posteriori do psiquismo. A vitimização pela violência na infância produz amplas seqüelas no desenvolvimento global de uma criança. Conforme as idéias apresentadas anteriormente, o abuso e a negligência são considerados falhas empáticas traumáticas que podem ter um longo impacto no desenvolvimento. Essas experiências, por sua vez, engendram intensas emoções negativas que fazem com que os sentimentos apropriados e suas necessidades sejam ignorados, invalidados ou violados. Nos ambientes abusivos, há uma comunicação limitada e um apoio restrito, o que dificulta o entendimento e a apropriada expressão das experiências emocionais. As crianças apresentam dificuldades para administrar suas intensas emoções negativas, o que resulta num descontrole ou num excessivo controle das emoções (Pavio \& Laurent, 2001).

O grau de cuidados insuficientes ou inadequados e a fase do desenvolvimento infantil em que ocorreram determinam a gravidade dos prejuízos decorrentes (Bowlby, 1988; Spitz, 1988). Quanto mais cedo ocorrer o trauma, mais devastadores serão seus efeitos (Shengold, 1999). Szejer e Stewart (1997) apontam que o odor conhecido da mãe, reencontrado após o nascimento, serve como referência tranqüilizadora ao bebê, que pode então sentir o parto não como uma ruptura, mas como uma mutação, uma forma de continuidade. Nos casos em que é abandonado pela mãe logo após o nascimento, o bebê sofre uma perda súbita de todas as suas referências sensoriais, o que dificulta a sua adaptação ao mundo, sendo essa experiência precoce determinante de uma falha na função protetora e integradora possivelmente decisiva na constituição psíquica. Considera-se que as privações ocorridas até 3 ou 5 anos de idade oferecem grande risco de danos psíquicos. Após esta faixa etária, a criança já desenvolveu recursos próprios, como a linguagem e a locomoção, que podem minorar os efeitos da privação (Bowlby, 1988, 1990). Quando as dificuldades tomam proporções excessivas, elas reativam o sentimento de desamparo infantil e o indivíduo se depara com uma impossibilidade de lidar com elas, refugiando-se em modelos relacionais que ilusoriamente representam proteção diante do sofrimento e da dor (Amendoeira, 1999).

Conforme muitos psicanalistas, privações significativas na infância determinam a constituição de um psiquismo frágil, que poderá apresentar mais tarde quadros psicopatológicos graves como a psicose, a personalidade anti-social (Winnicott, 1988) e a organização de personalidade borderline (Ogata e colaboradores, 1990). Nesses casos, existem padrões estruturados de impulsos, ansiedades e defesas primitivas, como a cisão e a identificação projetiva, que fixam a personalidade em algum ponto de equilíbrio precário alcançado, o qual é fortemente defendido por permitir a evasão das sensações de perda, de caos e de desintegração do eu (Amendoeira, 1999).

Abordando-se pontualmente os problemas comportamentais, pode-se dizer que as agressões físicas sofridas pelas crianças resultam num incremento de 
impulsos hostis que fazem com que as mesmas sejam agressivas com outras crianças e estejam mais propensas a atos anti-sociais na adolescência, bem como as predispõem a serem violentas com seus filhos e esposas (os) na idade adulta (Albornoz, 2001; Barnett, 1997; Bollas, 1992; EPOCH, 1993; J. Pires, 1999; Spitz, 1988). A relação de violência instalada na história de vida do agressor se instala na vida da vítima direta, das vítimas indiretas (familiares) e do grupo social (comunidade), revelando que há grande possibilidade de reprodução do ciclo de violência através das gerações ou entre os grupos (Affonso, Mota \& Pereira, 2000).

Freqüentemente, as vítimas de violência desenvolvem um repertório extenso de reações habituais destrutivas. A violência promove nos jovens uma busca alternativa de solução de problemas que envolve a participação em gangues criminosas, em assassinatos, em abusos, e leva ao uso de drogas e a um empobrecimento dos sentimentos (Brohl, 1996; Ferigolo, Arbo, Malysz, Bernardi \& Barros, 2000). O indivíduo torna-se incapaz de sentir gratidão e de interessar-se genuinamente por si e pelos outros. O outro é sentido como um estranho que tem uma única função: a de fornecer o que se espera dele (Amendoeira, 1999).

Knopp e Benson (1996) citam um estudo americano que aponta que crianças abusadas sexualmente apresentam muito mais sintomas físicos, psicológicos e comportamentais do que crianças não-abusadas. O sintoma mais comum entre estas crianças é o comportamento sexualizado que pode se apresentar das seguintes formas: jogos sexuais com bonecas, colocar objetos no ânus ou na vagina, masturbação excessiva e em público, comportamento sedutor, solicitude de estimulação sexual para com adultos ou outras crianças, conhecimento sexual inapropriado para a idade. Outros sintomas freqüentes são ansiedade, depressão, agressividade, problemas escolares, comportamento retraído, queixas somáticas, pesadelos, doença psicogênica, comportamento regressivo - enurese, encoprese, crises de birra, lamúria -, problemas comportamentais, desvalia e sintomas do transtorno de estresse pós-traumático. Os comportamentos sexualizados e os sintomas do transtorno de estresse pós-traumáticos ocorrem isoladamente com freqüência na infância, mas se associados acontecem com alta freqüência em crianças sexualmente abusadas.

Em crianças que sofreram repetidos e duradouros traumas de diversas ordens, os primeiros eventos traumáticos criam reações de surpresa, enquanto os subseqüentes criam um senso de antecipação e medo (Knopp \& Benson, 1996). Diante dessa perspectiva, há dados alarmantes: um estudo americano revelou que crianças traumatizadas pelo abandono parental, abuso ou negligência temem pela sua integridade física e emocional e têm reações de estresse semelhantes às reações pós- traumáticas de soldados veteranos da guerra do Vietnã (Brohl, 1996). Essa reação pode ser explicada pelo fato de que estímulos do cotidiano ativam lembranças de memórias aterradoras do passado, ocasionando reações de alarme automáticas e inapropriadas (Pavio \& Laurent, 2001).

As experiências esmagadoras reais ocorridas no curso do desenvolvimento de uma criança têm um efeito patogênico e destrutivo, diferente e mais profundo do que as fantasias infantis de ataques derivadas de impulsos sexuais e agressivos inconscientes que ocorrem mesmo na relação com pais carinhosos e cuidadosos. É fundamental que seja feita uma distinção da implantação normal da sexualidade infantil no universo familiar de uma violenta e intromissora implantação dessa sexualidade (Reitan, 1999; Shengold, 1999).

A grande questão centra-se no fato de que quando uma criança não tem a capacidade de resolver um problema vivencial excessivo para ela, ele passa a fazer parte de seu sentimento de identidade. Os traumas são vivenciados como definidores de vida. As crianças que tiveram uma experiência familiar que escapou a sua compreensão não conseguem organizar essa experiência contida em fantasias; elas armazenam o estado do self determinado pela situação desconhecida e a expectativa de um dia compreendê-las, para transformá-las em derivativos simbólicos ou esquecê-las (Bollas, 1992).

Bion (1970/1973) explica que existem pessoas que não conseguem tolerar a dor e a frustração, ou seja, elas sentem a dor, mas não podem ser levadas a descobri-la. Esses pacientes também não conseguem sentir o prazer. As experiências abusivas têm um poder aniquilador sobre o outro, pois destroem a sua individualidade, a sua dignidade, a sua capacidade de sentir profundamente alegria, amor e ódio, ou seja, suprimem a capacidade de um indivíduo de usar a sua mente, a sua capacidade de pensar racionalmente, a sua capacidade de conhecer e de testar a realidade (Shengold, 1999). Operações defensivas maciças são ativadas na mente, com o objetivo de proteger a psiquê: negação maciça, repressão, dissociação, anestesia do self, hipnose, identificação com o agressor, agressão voltada contra o self; o uso recorrente dessas defesas produz alterações profundas na personalidade da criança. Crianças traumatizadas podem apresentar amnésia com relação a estes eventos, enquanto outras podem não lembrar de fases de sua infância (Knopp e Benson, 1996). O terrível passa a não ser sentido, nem registrado na consciência, e os sentimentos são isolados e negados. A necessidade de se identificar e de ter a quem recorrer nos momentos de angústia leva a criança a manter a idealização do progenitor agressor, aumentando a negação da realidade, processo que Shengold (1999) chama de lavagem cerebral auto-imposta. Pelos mecanismos de divisão e isolamento, imagens fragmentadas boas e más do self e dos pais nunca são 
fundidas, comprometendo os sentimentos e o pensamento. A inibição do ego para lidar com o que não é compreendido resulta numa vulnerabilidade que instala o estado de viver como se a criança se tornasse um autômato, mecânico e obediente.

Os efeitos negativos das privações resultam em seqüelas no desenvolvimento da cognição, da linguagem e dos aspectos socioemocionais (Barnett, 1997). A falta de investimento parental gera dificuldades para que o eu infantil invista no seu corpo, nos seus pensamentos e nos outros (Violante, 1995). Dentre os imensos prejuízos ocasionados pelas situações de vitimização na infância, a obstaculização do pensamento decorre da incapacidade da criança para suportar a percepção da sua dura realidade e o sofrimento dela advindo. Como conseqüência, a capacidade inata para a investigação torna-se precária e a personalidade se configura de forma inábil para compreender e ajustar-se ao mundo, apresentando grave deficiência na função simbólica. São freqüentes os casos em que ocorre um impedimento do desenvolvimento do pensamento e da aprendizagem, que não estão relacionados a uma deficiência nas estruturas cognitivas, mas a uma inibição sintomática criada para remover uma situação de perigo geradora de ansiedade para o ego, que é conhecer a própria história (Freud, 1926/1980c; Lajonquiére, 1989). No entanto, visando à sobrevivência e ao ajustamento, possibilitadas por um ou mais vínculos satisfatórios que tenham vivenciado na infância, algumas pessoas traumatizadas desenvolvem talentos e forças incomuns (Shengold, 1999).

Diante da triste realidade da violência contra crianças e adolescentes, cabe salientar que a gravidade das situações de vitimização na infância e na adolescência pode ser impeditiva do desenvolvimento, fazendo com que esses indivíduos sejam afastados das suas famílias e encaminhados às instituições de proteção, com a intenção de propiciar-lhes a retomada do desenvolvimento. Cabe a essas instituições, mediante seus programas de acolhimento, proverem esses indivíduos do que é essencial para eles: as condições fundamentais para os seus desenvolvimentos.

\section{Considerações finais}

Tomando por base o estudo teórico, tem-se a inegável relação entre o desamparo e a dor, e os destinos da personalidade. A ausência de uma mãe continente implica a falta de um importante instrumento afetivo de elaboração e transformação das vivências do bebê. Nesses casos, faltará para esse bebê o amor da mãe e a sua empatia, que o ajudariam a organizar as suas pulsões libidinais e agressivas e a inaugurar o simbólico, constituindo-o como sujeito psíquico. Diante dessa ausência, o bebê, inundado pela angústia, não conseguirá estabelecer ou manter de forma equilibrada a integração do seu ser instintivo, cognitivo, afetivo e ambiental. Dentro dessa realidade, delineiam-se experiências invasivo-abusivas de diversas ordens. A intrusão do meio provocará uma dor intensa que, por ser vivenciada precocemente num momento de extremo desamparo, deixará seqüelas profundas na mente. No entanto, apesar das intempéries e dos sobressaltos, a mente buscará saídas: seja por meio de sintomas ou de pseudo-organizações como os falso-self; ou então, mais raras serão as saídas saudáveis, possíveis para pessoas especiais, cujas pulsões para a vida permitem que elas consigam "juntar os seus caquinhos" e, valendo-se deles, construir algo melhor.

As vivências abusivas tornam a mente e o corpo desprovidos de investimentos. A doença pode se instalar no psiquismo de tal forma que o desenvolvimento de padrões patológicos predomine e contamine totalmente a vida do indivíduo, jogando-o no mar revolto e sem saída da marginalização pela demência ou pela violência. Ou então, a vida pode propiciar ao indivíduo vitimizado experiências restauradoras que permitam que ele possa tornar-se sujeito do desejo e do fazer, desenvolvendo o potencial criativo do seu ser, de modo que as marcas do passado deixem de pesar e de obstaculizar as vivências do presente e as perspectivas do futuro. Mediante os cuidadores substitutos das instituições de abrigamento, dos lares de adoção e das psicoterapias, as chagas abertas pelos maus-tratos podem ser cicatrizadas, abrindo espaços na mente para o lúdico e o que advém dele: o trabalho, a política, as artes e mesmo o amor.

\section{Referências}

ABRAPIA - Associação Brasileira Multiprofissional de Proteção à Infância e Adolescência (1997). Maustratos contra crianças e adolescentes: proteção e prevenção: guia de orientação para educadores. Petrópolis, RJ: Autores \& Agentes \& Associados.

Acosta, S., Adúriz, F. \& Albarracín, D. (1998). Historias de victmización infantil: un análisis cualitativa de la construcción retrospectiva de episodios de violencia en la infancia y adolescencia. Revista Interamericana de Psicología, 32(2), 125-137.

Affonso, R., Mota, E. \& Pereira, A. (2000). A construção de um modelo clínico de atendimento psicológico a famílias vítimas de violência da cidade de São Paulo. Psichê, 5(2), 26-40.

Albornoz, A. C. (2001). A infância roubada - enfocando vivências de abuso. Revista da Saúde, 2, 38-45.

AMAS - Associação Municipal de Assistência Social (2000). Um exemplo de projeto de prevenção e 
combate à violência doméstica realizado na AMAS de Belo Horizonte. Primeira Mostra Nacional de Práticas em Psicologia do Conselho Federal de Psicologia e do Conselho Regional de Psicologia de São Paulo, SP.

Amendoeira, W. (1999). Dor psíquica. Revista Brasileira de Psicanálise, 33(3), 545-553.

Ammerman, R. \& Hersen, M. (1999). Assessment of family violence: Clinical and legal sourcebook. New York: John Wilrey \& Sons Inc.

Aulagnier, P. (1975/2001). La violencia de la interpretacióndo pictograma al enunciado. Buenos Aires: Amarrortu.

Aulagnier, P. (1984/1989). O aprendiz de bistoriador $e$ mestre-feiticeiro - do discurso identificante ao discurso delirante. São Paulo: Escuta.

Barnett, D. (1997). The effects of early intervention on treating parents and their children. Em M. J. Guralnick (Org.). The effectiveness of early intervention (pp. 147-167). Baltimore: Paul H. Publishing Co.

Bion, W. (1970/1973). Atenção e interpretação. Rio de Janeiro: Imago.

Bollas, C. (1992). A sombra do objeto: psicanálise do conhecido não-pensado. Rio de Janeiro: Imago.

Bowlby, J. (1988). Cuidados maternos e saúde mental. São Paulo: Martins Fontes.

Bowlby, J. (1990). Formação e rompimento dos vínculos afetivos. São Paulo: Martins Fontes.

Brohl, K. (1996). Working with traumatized children - A bandbook for healing. Washington DC: Child Welfare League of America Inc.

Costa, G. P. (1999). Relações familiares e aprisionamento psíquico. Psicanálise, 1(1), 65-74.

Dantas, A., Jr. (1999). Dor psíquica e o negativo: uma ilustração do trabalho do negativo no campo da experiência da dor. Revista Brasileira de Psicanálise, 33(3), 573-584.

EPOCH - End Physical Punishment of Children (1993). Hitting people is wrong and children are people too. Londres: [s. n.].

Farinatti, F., Biazus, F. \& Leite, M. (1993). Pediatria social. Rio de Janeiro: MEDSI.

Ferigolo, M., Arbo, E., Malysz, A., Bernardi, R. \& Barros, H. (2000). Aspectos clínicos e farmacológicos do uso de solventes. Jornal Brasileiro de Psiquiatria, 49(9), 331-341.

França, M. O. (1999). O inexorável da dor humana junto ao processo analítico. Revista Brasileira de Psicanálise, $33,555-572$.

Psico-USF, v. 9, n. 2, p. 211-218, Jul./Dez. 2004
Freud, S. (1895/1980a). Projeto para uma psicologia científica. Em Obras Completas: vol. I (pp. 381-512). Rio de Janeiro: Imago.

Freud, S. (1920/1980b). Além do princípio do prazer. Em Obras Completas: vol. XVIII (pp. 17-90). Rio de Janeiro: Imago.

Freud, S. (1926/1980c). Inibições, sintomas e ansiedades. Em Obras Completas: vol. XX (pp. 107-210). Rio de Janeiro: Imago.

Furniss, T. (1993). Abuso sexual da criança. Porto Alegre: Artes Médicas.

Kent, A. \& Waller, G. (2000). Childhood emotional abuse and eating psychopathology. Clinical Psychology Review, 20(7), 887-903.

Knopp, F. \& Benson, A. (1996). A primer on the complexities of traumatic memory of childhood sexual abuse. Brandom: Safer Society Press.

Kon, N. M. (2000). Exxodo e desamparo. Psychê, 4(6), 105-119.

Laia, S. (2001). A infância revista. Curinga, 15/16, 12-25.

Lajonquière, L. (1989). A clínica psicopedagógica entre o saber e o conhecimento. Educação e Sociedade, 61-70.

Mannoni, M. (1985). A relação fantasmática do filho com sua mãe. São Paulo: Martins Fontes.

Martínez, M. L. (1997). Concepciones parentales en la definicíon de negligencia infantil. Psychê, 6(1), 21-34.

Melsohn, I. (2001). Uma alternativa para o conceito de representação inconsciente. Revista Brasileira de Psicanálise, 35(1), 7-43.

Ogata, S., Silk, K., Goodrich, S., Lohr, N., Western, D. \& Hill, E. (1990). Childhood sexual and physical abuse in adult patients with borderline personality disorder. American Journal of Psychiatry, 147, 1008-1012.

Ortigues, M. C. \& Ortigues, E. (1988). Como se decide uma psicoterapia de criança. São Paulo: Martins Fontes.

Pavio, S. C. \& Laurent, C. (2001). Empathy and emotion regulation: Reprocessing memories of childhood abuse. Journal of Clinical Psychology, 57(2), 213-226.

Pereira, M. E. C. (2000). Mineirinho ou o horror do gozo: o desamparo e o outro. Psychê, 4(6), 124-124.

Pires, J. (1999). Violência na infância: aspectos clínicos. Em Amencar e Assembléia Legislativa do Rio Grande do Sul (Orgs.). Violência doméstica (pp. 61-70). Porto Alegre: [s. n.].

Pires, M. da P. (1999). Trauma e cura. Psychê, 3(3), 81-88.

Priore, M. Del. (Org.) (1999). História das crianças no Brasil. São Paulo: Contexto.

Reitan, R. (1999). The theory of seduction and abuse of 
children: Laplanche's generalized theory of seduction. Psylee and Logos, 20(2), 345-362.

Shengold, L. (1999). Maus-tratos e privação na infância: assassinato da alma. CEAPIA, 12.

Spitz, R. (1988). O primeiro ano de vida. São Paulo: Martins Fontes.

Szejer, M. \& Stewart, R. (1997). Nove meses na vida da mulher: uma abordagem psicanalitica da gravidez $e$ do nascimento. São Paulo: Casa do Psicólogo.

Violante, M. L. (1995). A criança mal-amada. Petrópolis, RJ: Vozes.
Winnicott, D. (1987). Privação e delinqüência. São Paulo: Martins Fontes.

Winnicott, D. (1988). O ambiente e os processos de maturação. Porto Alegre: Artes Médicas.

Zago, N. (2000). Quando os dados contrariam as previsões estatísticas: os casos de êxito escolar nas camadas socialmente desfavorecidas. Paidéia, 10(18), 70-80.

Recebido em julho de 2004 Reformulado em outubro de 2004 Aprovado em novembro de 2004

Sobre as autoras:

Ana Celina Garcia Albornoz é psicóloga e mestre em Psicologia Clínica pela PUCRS, atuando na Fundação de Proteção Especial do Rio Grande do Sul.

Maria Lucia Tiellet Nunes é psicóloga pela PUCRS, doutora em Psicologia pela Universidade Livre de Berlim e professora titular de Psicologia na Faculdade de Psicologia da PUCRS. 